\title{
Building Clinical Decision Support Systems for Clinical Practice in Poor Settings: Critical System Features
}

\author{
Jerome Addah \\ Department of Community Medicine, \\ School of Medicine and Health Sciences \\ University for Development Studies, \\ Tamale Ghana West Africa \\ Post Office Box TL 1883
}

\author{
Stephen Apanga \\ Department of Community Medicine, \\ School of Medicine and Health Sciences \\ University for Development Studies, \\ Tamale Ghana West Africa \\ Post Office Box TL 1883
}

\begin{abstract}
This study is a follow up on a previous one, it seeks to fill a critical knowledge gap, by providing information on the opinions of experts in a poor setting on the features of a computerized clinical decision support system they consider would aid their practice. Univariant analysis uncovered five systems features, albeit variants of one feature: the requirement to provide unique patient care recommendations.
\end{abstract}

\section{Keywords}

Clinical decision support systems, Ghana

\section{INTRODUCTION}

Clinical decision making is the art of arriving at an informed judgment regarding the optimal treatment needed by a patient [1]. Making this judgment call is the essence of everyday clinical practice, a key task is to balance personal experience with existing scientific knowledge [2]. Usually a physician would have to apply clinical and biomedical knowledge, invoke problem-solving skills, weigh the probabilities of various outcomes, and balance risk-benefits [2]. Notwithstanding arbitrary clinical decision making in disregard of available clinical evidence are rampant in both the developed, and developing world [3]. A nationwide audit using 439 quality indicators conducted in the US revealed that adults receive only half of recommended medical care [4], similarly the US institute of medicine estimated that up to 98000 residents were dying as a result of preventable medical errors [5]. In poor settings in Africa with high health stakes characterized by a high disease burden and a small work force with minimal training, the need for good clinical decision making is even more compelling [6]Improvements in clinical decision making may be accomplished through training [7, 8], and the adoption of computerized clinical decision support systems[9]. Adoption of computerized clinical decision support systems may also lead to improvements in prescribing practices[10], reduce medication errors [11], enhance the delivery of preventive care services [12], and improve adherence towards recommended care standards [13]. Successful implementation of computerized clinical decision support systems (CCDSS) is a complex process [14], thus failures are bound [15]. Efforts to determine CCDSS features implicated in clinical practice improvements have relied on the opinions of experts in the developed world [15], little is known about the opinions of experts in resource -limited settings, even though it is well documented that successful implementation of CCDSS also depends on the clinical practice settings [16]. This paper seeks to fill this knowledge gap.

\section{METHODS AND MATERIALS m}

This study is the result of a survey among practicing physician doctors at a Ghanaian Teaching Hospital affiliated to a Medical School using a questionnaire designed to investigate skills in ICT, and physician attitudes towards incorporating ICT into their practice and the medical school curriculum. Physicians who returned their completed questionnaires were regarded as having given their consent to participate in this study.

\subsection{Setting and Participants}

A cohort of 98 physicians of the Tamale Teaching Hospital was served questionnaires. The participating physicians were informed of the Purpose of the study, the requirement to complete a questionnaire, and the general content of the questionnaire. They were also told that their participation in the study was voluntary and that no personal identifiable information was going to be taken. The teaching hospital is located in Tamale the metropolitan capital of the northern region of Ghana. It is one of the third generations of teaching hospitals to be established in the country. The hospital is affiliated to the medical school of the University for Development Studies. At the moment, the hospital has no public access to computers for medical students, it however provides broadband internet access for staff and students, and computers are not available in the library for students to use, currently the hospital is the only clinical training site for medical education in northern Ghana.

\subsection{Survey Instrument}

The physicians were asked the following questions pertaining to: instructional methods, educational tools, ICT skill types: Basic (able to do basic word processing and use the internet), Intermediate (Have mastered the basics and have developed additional skills, including the use of different software programs), Advanced (Knowledgeable about hardware and software), ability to perform certain task with computers, frequency of computer use, they were also given a list of desired EMR system capabilities and then asked to judge if those capabilities were; Relevant (I would be much more likely to use a system with this capability, I would however not use a system that lack it.), Non- Relevant (my decision to use a system would be unaffected by the presence of this capability), I don't know ( the meaning or implication of this capability is not clear to me.). A drafted version of the questionnaire was administered to students $(n=100)$ in June, 2011. Internal reliability (Cronbach's alpha) obtained from combining items with ordinal responses was 0.82 (95\% CI) for intra class correlation coefficient; 0.79 to 0.88 . The 
questionnaires were administered to the physicians who consented to participate in the study.

\subsection{Data Analysis}

Statistical analysis was performed using STATA (version 11.0, StataCorp. 2009). In order to identify responding

\section{RESULTS}

Overall 140 physicians received survey questionnaires, out of which 120 of them returned their questionnaires, 22 questionnaires were discounted due to incomplete data, physician's computer use habits, an analysis of frequencies of items derived from responses to questions related to frequent computer use was undertaken. Categorical variables relating to EMR system capabilities were analyzed using chi-square.

resulting in a response rate of $70 . .0 \%$. The mean age for responding physicians was 29 years with a distribution of $29 \pm$ 1.4 (mean \pm standard deviation). The physicians were mostly men, majority used a computer daily, while a small number said they don't use computers (Table 1).

Table1. Participant (n=98) Demographics'

\begin{tabular}{|l|l|}
\hline & $\mathrm{n}(\%)$ \\
\hline Age & $29.0 \pm 1.4$ \\
\hline Gender & \\
\hline Female & $41(42.0 \%)$ \\
\hline Male & $57(58.0 \%)$ \\
\hline
\end{tabular}

Responding physicians desired a clinical decision support system with the ability to provide advice on the care of specific patients (Table 2). They also preferred that the system be able to provide several other recommendations, while also been able to explain the rationale behind each recommendation it gives on the care of specific patients (Table 2)

Table 2 A contingency table describing proportions of physicians who judged CDSS patient care features as either Relevant

\begin{tabular}{|l|c|c|c|l|}
\hline $\begin{array}{l}\text { system Capabilities related to patient care \& } \\
\text { management }\end{array}$ & $\begin{array}{c}\text { Total not } \\
(\mathrm{n}=98)\end{array}$ & $\begin{array}{c}\text { Relevant } \\
(\mathrm{n}=59)\end{array}$ & $\begin{array}{c}\text { Non Relevant } \\
(\mathrm{n}=39)\end{array}$ & P -Value \\
\hline $\begin{array}{l}\text { when the system provides medical advice on the care } \\
\text { of specific patients, it always provides multiple } \\
\text { alternative recommendation }\end{array}$ & $65(66.3 \%)$ & $48(81.4 \%)$ & $17(43.6 \%)$ & 0.0001 \\
\hline $\begin{array}{l}\text { the system can clearly explain the rationale for advice } \\
\text { it gives on the care of patients }\end{array}$ & $64(65.3 \%)$ & $46(78.0 \%)$ & $18(46.2 \%)$ & 0.0012 \\
\hline $\begin{array}{l}\text { Users can browse the information in a system as well } \\
\text { as asking it to provide advice about care of specific } \\
\text { patients }\end{array}$ & $64(65.3 \%)$ & $48(81.4 \%)$ & $16(41.0 \%)$ & $<0.0001$ \\
\hline
\end{tabular}

Regarding the integrity and security of a clinical decision support system, two system features were identified to be significant (Table 3). One feature relates to the integrity and validity of recommendations provided by a clinical decision support system, while the other relates to the ability of a clinical decision support system to guarantee the confidentiality of patient information 
Table 3 CDSS security features considered to be either relevant or non-relevant by responding physicians

\begin{tabular}{|c|c|c|c|c|}
\hline System integrity \& Security Capabilities & $\begin{array}{c}\text { Total } \\
(\mathrm{n}=98)\end{array}$ & $\begin{array}{c}\text { Relevant } \\
(\mathrm{n}=59)\end{array}$ & $\begin{array}{c}\text { Non } \\
\text { Relevant } \\
(\mathrm{n}=39)\end{array}$ & P -Value \\
\hline $\begin{array}{l}\text { the system has been demonstrated in research studies to provide treatment } \\
\text { recommendations at least as accurate as human consultants }\end{array}$ & $67(68.4 \%)$ & $47(79.1 \%)$ & $20(51.3 \%)$ & 0.0031 \\
\hline level of confidentiality and security must be better than the paper record & $70(71.4 \%)$ & $54(91.5 \%)$ & $16(41.0 \%)$ & $<0.0001$ \\
\hline
\end{tabular}

\section{DISCUSSION}

Clinical decisions made by physicians vary from one practice to the other, depending on the size of the practice, its geographical location, the capabilities of physicians, treatment policies and protocols, and organization of the practice [16]. Arriving at the most optimal clinical decision therefore is a complex process requiring finesse and wisdom, usually a physician would have to integrate scientific evidence, peculiar patient characteristics and wishes, together with other nonclinical factors in process the Art of Medicine. Physicians often adopt this process from different perspectives, influenced by varying levels of wisdom, experience, understanding and sensitivity; culminating in inconsistent patient outcomes. In poor settings where logistical and resource constraints have conspired to reduce this traditional art of medicine to the level of a physician's experience informed through repeated trial and error.

In view of this clinical decision support systems are being seen as avenues for reducing, if not eliminating the over reliance on personal experience in the clinical decision making process, particularly in poor settings with the recent emphasis on evidence based medicine, the need for clinical decision support systems has become critically important. However what system features are needed in a CDSS to make it effective is a matter of great debate. Through this study five system feature have been identified, that can be considered as critically for successful implementation of CDSS in environs that are constrained by logistics and resources. The identified system features emerge out of a singularly thematic concept: that of providing patient cantered clinical advice. Despite this, individually the identified system features address specific challenges in making clinical decisions in poor settings.

In a systematic review of published literature to determine system features that make effective CDSSs, Kawamoto, and colleagues [9] reported four unique features. The results of this study are consistent with their findings. In fact they reenforce one particular system feature: the need to provide unique patient recommendations, instead of just assessments of their conditions. The results of the current study reveal further its other variants: therefore, not only must a CDSS be able to provide automated recommendations of the care of specific patients, it must in addition be able to provide other such recommendations, and also be able to provide a rationale for each recommendation it provides to physicians.

The essence of having a CDSS provide recommendations is, to help mitigate the confounding factors that turn to sway clinical decisions away from optimal paths as may be dictated by clinical evidence. Among such confounding factors are; the wishes and preferences of patients, a physician's personal characteristics, and external influences of a physician's professional colleagues. The wishes and preferences of patients can be persuasive arguments against prevailing clinical evidence. Escher and colleagues [17]) report in their study that $71 \%$ of physicians attributed their decision to admit their patients to the intensive care unit to the wishes and preferences of their patients. The moral argument in favour of the wishes and preferences of patients is that, if patients get what the want, they are more likely to adhere to treatment regimens. Several studies $[18,19]$ report the influence that a physician's idiosyncrasies have on his or her clinical decision making. The network of professional interactions that a physician engages in also influences their clinical decision making. Physicians who are exposed to new medical trends through conferences, seminars, and workshops are more likely to be clinically well informed than their peers who do [20]. In poor settings opportunities for such refresher training are either rare or non-existent. The availability of CDSS may therefore serve as a check against the tendency to compromise clinical evidence in favour of the wishes and caprices of patients and physicians.

The identified CDSS features reported in this study, as well as those reported by other studies would not guarantee the effectiveness of a CDSS, particularly in poor settings. The effectiveness of a CDSS involves interactions between technologies and organizations, deciding on the best path that guarantees success or prevent failures is a complex process [14]. A CDSS is only as good as its knowledge base [21]. A CDSS with the ability to evolve its knowledge base may prove effective in poor settings where knowledge resources are either not available or difficult to come by.

\section{CONCLUSION}

This study has uncovered five individual system features that are critical for effective implementation of computerized clinical decision support systems in poor settings.

\section{ACKNOWLEDGMENTS}

The students who willing participated in this study are greatly indebted,

\section{REFERENCES}

[1] Hardy D, Smith, B. , ;. Decision making in clinical practice. J Anaesth 12008;9: :19-21.

[2] Bhugra D. Decision making in psychiatry: what can we learn? Acta Psychiatr Scan 12008;118: 1-3.

[3] Whitney S, Holmes-Rovner, M, Brody, H, . . Beyond shared decision making: An expanded typology of medical decisions. Med Decis Making 12008;28:: ;699705 . 
[4] McGlynn E, Asch, SM, Adams, J, Keesey, J, Hicks, J, DeCristofaro, A, . The quality of health care delivered to adults in the United States. N Eng. J Med 12003;;348: 2635-45.

[5] Kohn L, Corrigan, JM, Donaldson, MS, . To err is human: building a safer health system: Washington, : National Academy Press, 1999.

[6] Chen L, Evans, T. Anand, S., Bou,J. I. H. Brown HC, M. Cueto, M. Dare, L Dussault, G. Elzinga, G. Fee, E . Habte, D P. Hanvoravongchai P, Jacobs, M Kurowski, C, Michael SP-AM, N. Sewankambo, G. Solimano, B. Stilwell, A. de Waal, S. Wibulpolprase, S. . Human resources for health overcoming the crisis. . Lancet, $12004 ; 364$.

[7] Prosser H, Walley, T. . New drug uptake: qualitative comparison of high and low prescribing general practitioners' attitudes and approach. Fam Pract $1003 ; 2: 583-91$

[8] Schumock G, Walton, SM, Park, HY, ., ;. . Factors that influence preribing decisions. Ann Pharmacother 12004;38: :557-62.

[9] Kawamoto KH, CA Balas EA, Lobach, DF. Improving clinical practice using clinical decision support systems: a systematic review of trials to identify features critical to success. BMJ online 12005 .

[10] Bennett JW GPCrafim, trials. masrorc, . Med J Aust 12003;;178:: 217-22.

[11] Kausha 1R, Shojania KG, Bates DW.. :. Effects of computerized physician order entry and clinical decision support systems on medication safety: a systematic review. Arch Intern Med Decis Making 12003;;163: 1409-16.
[12] Balas EA WS, Barb CT, Blumenthal D, Boren SA, Brown GD. . Improving preventive care by prompting physicians. Arch Intern Med 1.2000;160:: ;301-8.

[13] Shiffman R, Liaw Y, Brandt CA, Corb GJ. . Computerbased guideline implementation systems: a systematic review of functionality and effectiveness. J Am Med Inform Assoc 11999;;6: 104-14.

[14] Wears R, , Berg, M., . Computer technology and clinical work ; still waiting for Godot. JAMA 12005;293 1223-38.

[15] Kensaku Kawamoto KH, CA E Balas EA, Lobach, DF. Improving clinical practice using clinical decision support systems: a systematic review of trials to identify features critical to success. BMJ online 12005.

[16] McKinley J, Potter DA, Feldman HA.., ;:. Non-medical influences on medical decision making. Soc Sci Med 11996;42: 769-76.

[17] Escher M, Perneger, TV, Chevrolet, JC. . National questionnaire survey on what influences doctors' decisions about admission to intensive care. BMJ 12004;;329: 1-5.

[18] Hamann J, Adjan S, Leuchat S, Kissling W. Psychiatric decision making in the adoption of a new antipsychotic in Germany. Psychiatric Services 12006;;57: 700-3.

[19] Modi S, Whetstone LM, Cummings DM. . Influence of patient and physician characteristics on percutaneous endoscopic gastrostomy tube decision-making. . J Pall Med 12007;;10: :359-66.

[20] Schumock GT WS, Park HY, et al. Factors that, Pharmacother ipdA. 12004 38:: 557-62.

[21] Sim I, Gorman, P, Grenes RA, Haynes, RB, Kaplan, B, Lehmann, H,. Clinical decision support systems for the practice of evidence-based medicine. J Am Med Informatics Assoc 12001;8: 527-34. 